\title{
Limited Laminectomy and Restorative Spinoplasty in Spinal Canal Stenosis
}

\author{
Sukhbir Singh Sangwan, Rakesh Garg, Paritosh Gogna, Zile Singh Kundu, Vinay Gupta, Pradeep Kamboj \\ Department of Orthopaedics, Paraplegia and Rehabilitation, Pt BD Sharma Post Graduate Institute of Medical Sciences, Rohtak, India
}

\begin{abstract}
Study Design: Prospective cohort study.
Purpose: Evaluation of the clinico-radiological outcome and complications of limited laminectomy and restorative spinoplasty in spinal canal stenosis.

Overview of Literature: It is critical to achieve adequate spinal decompression, while maintaining spinal stability.

Methods: Forty-four patients with degenerative lumbar canal stenosis underwent limited laminectomy and restorative spinoplasty at our centre from July 2008 to December 2010. Four patients were lost to follow-up leaving a total of 40 patients at an average final follow-up of 32 months (range, 24-41 months). There were 26 females and 14 males. The mean \pm standard deviation (SD) of the age was $64.7 \pm 7.6$ years (range, 55-88 years). The final outcome was assessed using the Japanese Orthopaedic Association (JOA) score. Results: At the time of the final follow-up, all patients recorded marked improvement in their symptoms, with only 2 patients complaining of occasional mild back pain and 1 patient complaining of occasional mild leg pain. The mean $\pm S D$ for the preoperative claudication distance was $95.2 \pm 62.5 \mathrm{~m}$, which improved to $582 \pm 147.7 \mathrm{~m}$ after the operation, and the preoperative anterio-posterior canal diameter as measured on the computed tomography scan was $8.3 \pm 2.1 \mathrm{~mm}$, which improved to $13.2 \pm 1.8 \mathrm{~mm}$ postoperatively. The JOA score improved from a mean $\pm S D$ of $13.3 \pm 4.1$ to $22.9 \pm 4.1$ at the time of the final follow-up. As for complications, dural tears occurred in 2 patients, for which repair was performed with no additional treatment needed.

Conclusions: Limited laminectomy and restorative spinoplasty is an efficient surgical procedure which relieves neurogenic claudication by achieving sufficient decompression of the cord with maintenance of spinal stability.
\end{abstract}

Keywords: Lumbar spine; Lumbar canal stenosis; Decompression; Limited laminectomy; Spinoplasty

\section{Introduction}

Degenerative lumbar spinal stenosis is the most common cause of lower backache and lower extremity discomfort and disability in elderly patients. The incidence of acquired lumbar stenosis is approximately 1 per 1,000 in individuals older than 65 years [1]. With the increasing longevity of our population and a continually rising pro- portion of middle-aged and elderly patients, the problem of lumbo-sacral pain is a significant health care issue [2]. Degenerative spinal stenosis typically becomes symptomatic when patients are in their middle to late 50s or early 60s [3]. It is three to five times more common in women than men and most commonly affects the L4-L5 segment followed by the L3-L4 segment [4].

It is generally accepted that surgery is indicated if well-

Received Mar 28, 2013; Revised Aug 14, 2013; Accepted Aug 24, 2013

Corresponding author: Paritosh Gogna

Department of Orthopaedics, Paraplegia and Rehabilitation, 2UH/11-J Medical Enclave, Pt BD Sharma Post Graduate Institute of Medical Sciences, Rohtak, Haryana, India 124001

Tel: +91-8607773555, Fax: +91-01824-228106, E-mail: paritosh.gogna@gmail.com 
conducted conservative management fails. Decompressive laminectomy has been widely used as an operative treatment for lumbar canal stenosis [5,6]. Classically, surgical decompression involves extensive removal of the posterior elements including the lamina, spinous processes, interspinous ligaments, ligamentum flavum and occasionally the facet joints [7]. The advantages of conventional laminectomy, i.e., good visibility, a large working space and sufficient decompression, are offset by the fact that resection of an osteoligamentous structure causes secondary spinal instability [8]. Long segment spinal fusion, advocated for postoperative instability, is associated with higher complication rates and expenses [9].

It is critical to achieve adequate spinal decompression in spinal canal stenosis while maintaining the spinal stability [10]. However, too limited a decompression can be accompanied by re-growth of the bone that affects the long term results. The best option would be an adequate decompressive limited laminectomy with a nonfusion technique of preserving the posterior ligament complex integrity [11]. The integrity of the posterior ligament complex (spinous process, intraspinous ligaments and supraspinous ligaments) and paraspinal muscles minimizes the risk of developing de novo postoperative spinal instability. The present study was done to evaluate the clinicoradiological outcomes and complications of limited laminectomy and restorative spinoplasty in spinal canal stenosis.

\section{Materials and Methods}

We performed limited laminectomy and restorative spinoplasty in 44 patients with degenerative lumbar canal stenosis at our centre from January 2008 to December 2010. Forty patients were available for the outcome analysis at the time of the final follow-up. There were 26 females and 14 males. The mean \pm standard deviation (SD) for the age was $64.7 \pm 7.6$ years (range, $55-88$ years) and the average final follow-up was 32 months (range, 24-41 months). The distribution of the site of the involved segments and level of decompression was as follows: L4L5 ( $\mathrm{n}=20), \mathrm{L} 3-\mathrm{L} 4$ and L4-L5 ( $\mathrm{n}=10), \mathrm{L} 4-\mathrm{L} 5$ and L5-S1 $(\mathrm{n}=6), \mathrm{L} 5-\mathrm{S} 1(\mathrm{n}=2)$ and L3-L4 $(\mathrm{n}=2)$. The clinical diagnosis was made from the patient's history and a thorough general physical and neurological examination. It was correlated with plain radiography, magnetic resonance imaging and computed tomography (CT) scans. Radio- logical assessment was done to assess the interpediclular distance, facet joint hypertrophy, the presence of spondylolisthesis and the presence of stenosis with or without superimposed arthrosis. Bending films of the lumbar spine in the lateral view were done to assess dynamic instability. In the CT scans, anything less than $11 \mathrm{~mm}$ for the anterioposterior (AP) diameter for the lumbar spine was considered abnormal [12]. Inclusion criteria were patients with failed conservative treatment for 2 months with diminution of motor power in the lower limbs, hypoesthesia in the soles and/or in the saddle area, and disturbance of sphincter functions or neurological claudication (walking distance $<200 \mathrm{~m}$ ). Exclusion criteria were an AP diameter of the canal of more than $11 \mathrm{~mm}$ on the CT scan, pure lateral canal stenosis, a history of previous spinal surgery, severe chronic or co-morbid diseases and suspected malignancy, fracture of the spine, spondylolisthesis greater than Meyerding grade II, peripheral neuropathies, peripheral vascular disease and spinal cord tumour.

Patients were given an explanation in detail about the surgery and rehabilitation programme. All patients were subjected to surgery under general anaesthesia after giving informed consent. The patients were positioned prone on wooden blocks, designed indigenously as an alternative to the Relton Hall frame [13]. The procedural approach was through a midline incision over the stenotic vertebrae in all cases. The paraspinal muscles were reflected on both sides subperiosteally, while preserving the supraspinous and interspinous ligaments, and the posterior portion of the vertebral arch was exposed. The spinous process was cut in an L-shape at the junction of the proximal one-third and distal two-thirds. The distal two-thirds of the cut spinous process was caudally reflected together with the distal interspinous-supraspinous ligament complex (Fig. 1). Limited laminectomy was performed whereby the corresponding vertebral laminae were removed along with the hypertrophied ligament flavum and the offending osseous or discogenic compressing structures. Except in four patients, with associated foraminal stenosis, we did not resort to excision of the facet joints. Adequacy of decompression was assessed by a probe.

After decompressing the neural tissue, the spinous process was repositioned and reconstructed with tight suturing using nonabsorbable suture material (spinoplasty) (Figs. 2, 3). The incision was closed in layers. The 
operative findings were recorded and correlated with the clinico-radiological impression. Isometric abdominal and lower extremity exercises were started on the second postoperative day. As the patient's strength increased,

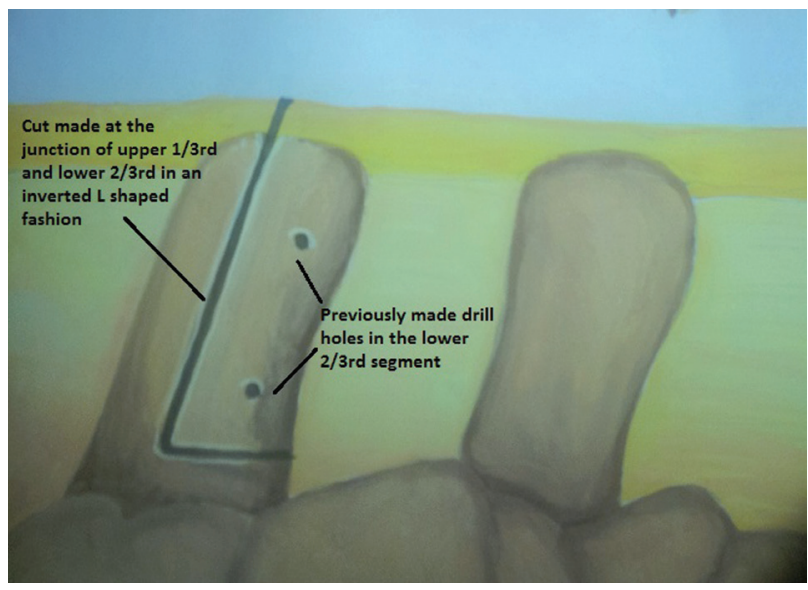

Fig. 1. Spinous process was cut at the junction of the upper $1 / 3 \mathrm{rd}$ and the lower $2 / 3$ rd and drill holes were made for the passage of sutures at a latter stage. isotonic leg exercises were also started. Patients were allowed to move out of the bed as soon as possible with a spinal brace. Patients were instructed to avoid prolonged sitting for the first 3 weeks. Lifting, bending, and stopping were gradually restarted after the sixth week. Patients were reviewed clinically and radiologically at 2 weeks (at the time of the removal of sutures) and thereafter every month for 3 months, then once every 3 months for 1 year and thereafter twice a year. A postoperative CT scan was done to measure the diameter of the spinal canal. Along with a neurological examination, patients were assessed for any signs of deep vein thrombosis, local haemorrhage and haematoma at the operative site. The Japanese Orthopaedic Association (JOA) score before surgery and at the time of the final follow-up were compared.

\section{Results}

All of the patients had ligamentum flavum hypertrophy, 13 had facet joint hypertrophy, 6 had thickening of the
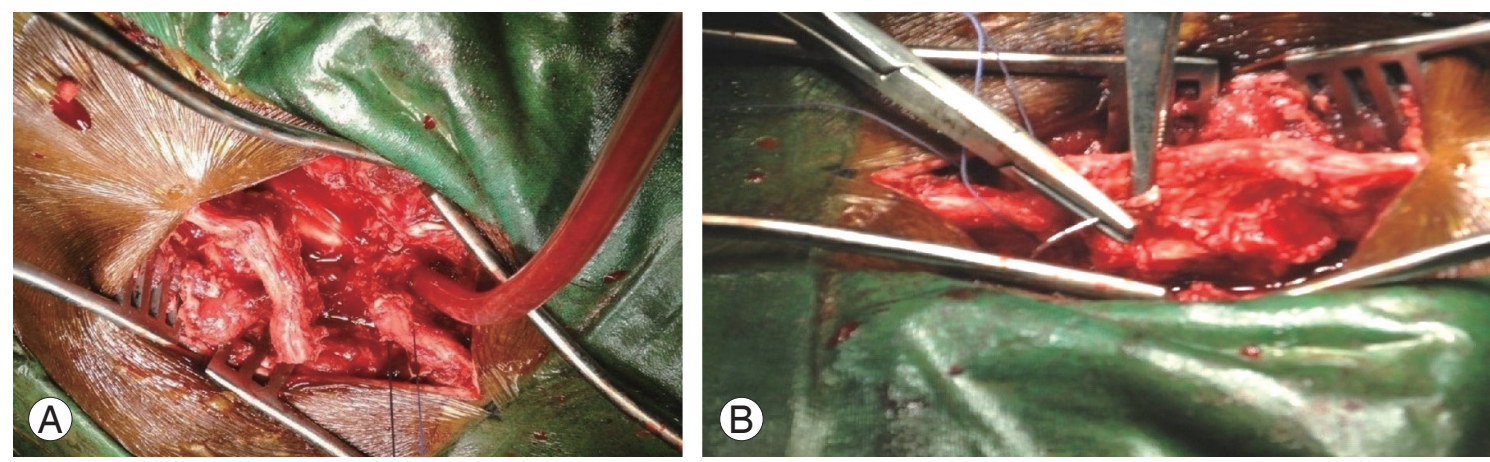

Fig. 2. (A, B) Caudally retracted distal 2/3rd of the spinous process sutured back to the proximal 1/3rd through a drill hole made earlier.
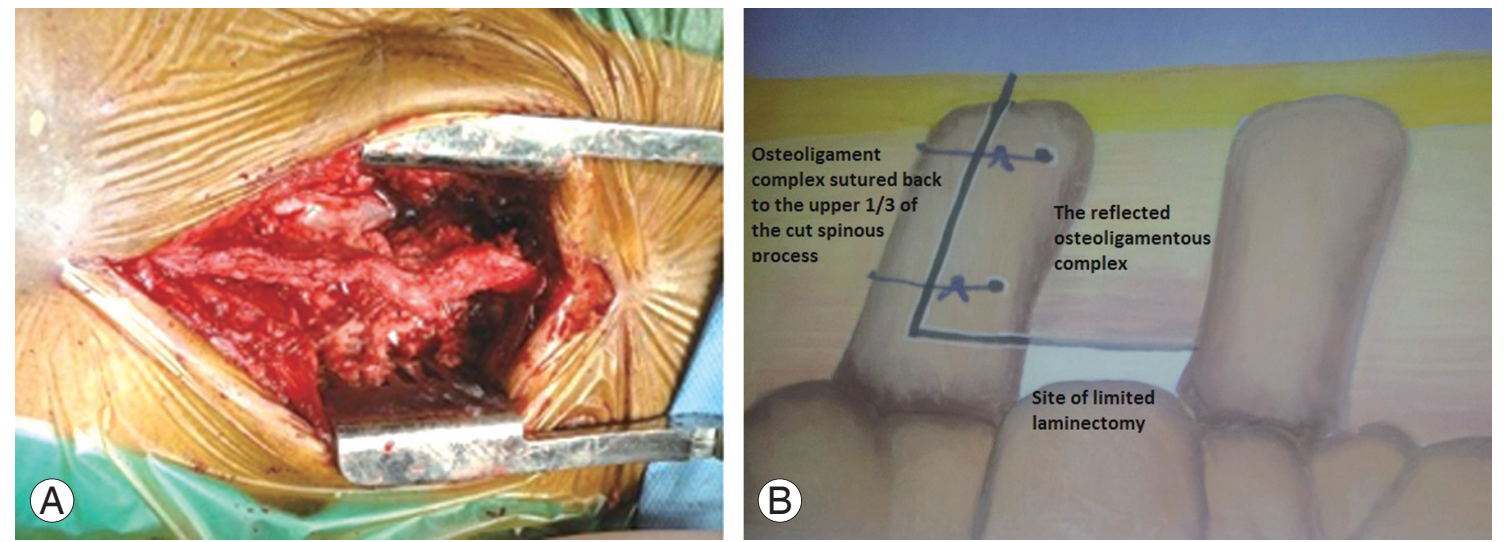

Fig. 3. (A, B) Sutured spinous process after achieving decompression. 
laminae and 12 patients had associated disc herniation. The average operation time was 108 minutes (range, 90120 minutes). The average blood loss during the surgery was $150 \mathrm{~mL}$ (range, $120-200 \mathrm{~mL}$ ) and none of our patients required a blood transfusion. The mean $\pm \mathrm{SD}$ for the AP canal diameter as measured on the CT scan preoperatively was $8.3 \pm 2.1 \mathrm{~mm}$ and postoperatively was $13.2 \pm 1.8$ $\mathrm{mm}$. No patient had difficulty in doing active flexionextension movements, active lateral bending or rotations (Fig. 4). Patients experienced marked relief from the neurogenic claudication and they observed marked improvement in their preoperative stooping posture. The mean $\pm \mathrm{SD}$ for the preoperative claudication distance was $95.2 \pm 62.5 \mathrm{~m}$ which improved to $582 \pm 147.7 \mathrm{~m}$ after surgery. At the time of the final follow-up, only 2 patients complained of occasional mild back pain and 1 patient of occasional mild leg pain. There was no postoperative deformity and none of our cases suffered from failed back syndrome or nerve root injury. There was no significant difference in the sagittal alignment as seen on flexion-extension X-rays. As for complications, dural tears occurred in 2 patients; the tears were repaired and needed no additional treatment.

The mean \pm SD for the preoperative JOA score was $13.3 \pm 4.1$ which improved to $22.9 \pm 3.2$. Improvement in the JOA scores was significant by the paired Student's $t$-test. Scores of each item categorised in the JOA score improved in all cases and the change in scores was statistically significant for each item $(p<0.05)$.

\section{Discussion}

Degenerative spinal stenosis refers to a pathological condition causing compression of the contents of the osteoligamentous vertebral canal and/or the intervertebral foraminal canal, particularly the neural structures. It is one
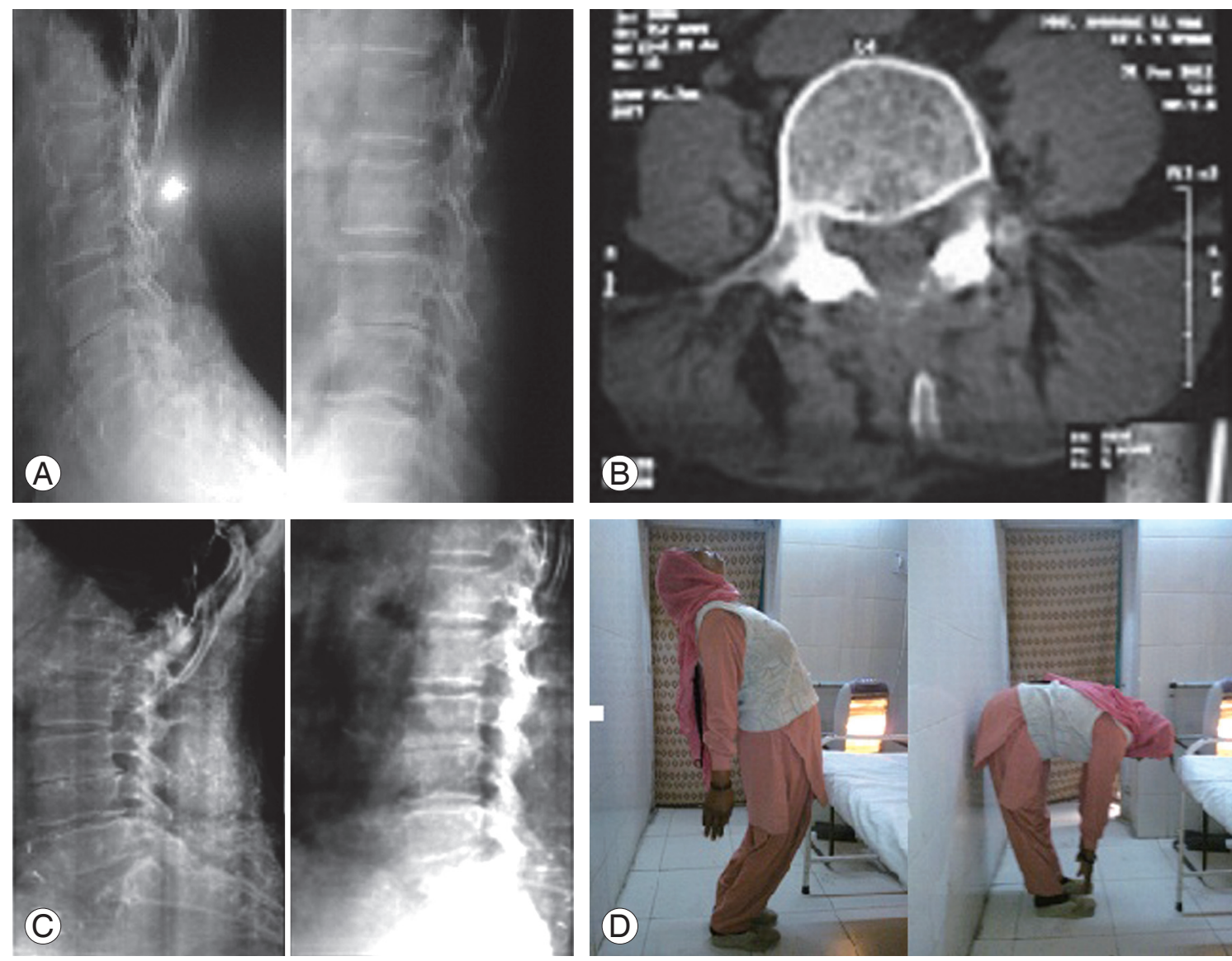

Fig. 4. (A) Preoperative radiographs of a 72-year-old female with lumbar canal stenosis and degerative disc disease at $L 3-L 4$. Limited laminectomy and restorative spinoplasty was done. (B) Postoperative computed tomography scan showing a wide lumbar canal and retained spinous process. (C) Follow-up radiographs showing well-maintained sagittal alignment at the 36-month follow-up. (D) Extension and flexion clinical photographs of the same patient at the 36-month follow-up. 
of the most common spinal disorders affecting people older than 50 years of age and occurs as the end stage of long-standing disc disease, often at several lumbar segments. Decompressive surgery has been the method of choice for many years for those with progressive neurological symptoms. Preservation of the posterior elements is the most important factor in the success of decompression surgery for lumbar canal stenosis [14], but occurrence of postoperative instability and restenosis has been a shortcoming of laminectomy [15]. Despite affording a wide decompression, laminectomy or "unroofing" of the spinal canal can cause destruction or impairment insufficiency of the pars interarticularis or facet joints, resulting in segmental instability and paravertebral muscle atrophy [16]. Fenestration has been developed to solve this problem of laminectomy [17]. This method, which does not remove the midline osteoligamentous structure, preserves spinal stability but at the cost of limited access to the nerve tissues, leading to insufficient decompression in the lateral recesses, especially in patients with narrow and steep facet joints. The potential risk for neural injury in a small working space is also a problem $[8,18,19]$. Recently, the addition of fusion techniques and instrumentation for surgical decompression has become accepted; however, indications for these procedures are still unclear. On the other hand, as Resnick et al. [20] reported in their multi center study, there is no proof in favor of fusion procedures or instrumentation for degenerative lumbar stenosis without deformity or preoperative instability. Turner et al. [5] found no difference in the outcomes between patients with or without fusion in a comprehensive literature review, with a satisfaction rate of about $70 \%$ for all procedures. Grob et al. [21] showed no advantage of instrumented fusion over laminectomy without arthrodesis in a randomized controlled trial of 45 patients with degenerative spinal stenosis and no spondylolisthesis.

The mean canal diameter at all stenotic levels was 8.3 $\mathrm{mm}$. The normal mid-sagittal diameter of the lumbar vertebral canal is defined as greater than $12 \mathrm{~mm}$. Relative stenosis occurs when the canal diameter is between 10 $\mathrm{mm}$ and $12 \mathrm{~mm}$, and absolute stenosis is defined as less than $10 \mathrm{~mm}$ [22]. These measurements, however, are only guidelines. The extent of compression of the nerve roots and cauda equina and the patient's signs and symptoms are more important than the canal diameter [23]. There is no consensus on the prognostic significance of the degree of preoperative spinal canal stenosis. The relationship between the severity of the preoperative radiographic findings and surgical outcomes following decompression for lumbar degenerative spinal canal stenosis is unclear [24-26]. Degenerative spinal canal stenosis with neurogenic claudication, however, is physiologically distinct from these more acute types of neurologic compression. The slowly progressive compression appears to afford the roots time to physiologically adjust to the changing situation so that many patients with severe narrowing of the spinal canal remain asymptomatic. There is, however, a subgroup of patients with milder degrees of stenosis who clearly present with neurogenic claudication suggesting that factors intrinsic to the roots may diminish their ability to physiologically adjust to compression

Minimization of bone and ligament removal results in greater preservation of the normal motion of the lumbar spine after surgery. The preservation and integrity of the spinous process, supraspinous ligament and interspinous ligament complex in spinoplasty prevents instability following decompressive laminectomies. In a cadaveric study, the biomechanical effect of graded removal of posterior elements associated with the various approaches was investigated. This study suggested that preservation of the posterior spinal elements could minimize the risk of developing de novo postoperative changes in spinal alignment and/or acceleration of facet and disc degeneration [16]. Loss of the spinous process and ligaments makes the paraspinal muscles puny and compromises their function. Due to the loss of levers, the lumbar spine may not cope up with stress. Therefore, every effort should be made to preserve each component of the posterior complex unit.

The interspinous ligament and osseous integrity play a vital role in maintaining the segment stability of the lumbar spine. The load sharing among different ligaments predicted under a flexion load suggests that the supraspinous ligament carries the greatest load, followed by the ligamentum flavum, capsular ligament, intertransverse ligament, and interspinous ligament. The transection of ligaments increases the flexibility of the joint, the strains on the rest of the ligaments as well as the moment on the disc [13]. In a cadaveric study on porcine lumbar spine, Chen et al. [27] concluded that under flexion, the intervertebral displacement on the adjacent disc with a complete laminectomy was statistically larger than with an intact posterior osseous-interspinous ligament complex. Therefore, the integrity of the posterior complex (spinous 
process-supraspinous ligament-spinous process) acts as a tension band in flexion and helps stabilize the decompressed spine.

The evolution of minimally invasive techniques like microendoscopic decompression has led to safe and effective applications for the treatment of lumbar canal stenosis with the need for only a small-skin incision and gentle tissue dissection but symptomatic outcomes have remained similar or less fruitful than with conventional surgical procedures [17]. Endoscopic procedure is a relatively new technique and has a long learning curve. Once the surgical skills are perfected, it can be performed safely and effectively [28]. Our study has its own set of limitations, which include a relatively small sample size and lack of comparison. The strength of the study is that it is a single centre study with the same surgical team.

\section{Conclusions}

Limited laminectomy and restorative spinoplasty surgery has significant advantages compared to standard laminectomy for lumbar canal stenosis. It has yielded encouraging results in relieving neurogenic claudication by increasing the canal diameter and maintaining the spinal stability. However, we suggest that comparative studies with a larger sample size are required to further support this observation.

\section{Conflict of Interest}

No potential conflict of interest relevant to this article was reported.

\section{References}

1. Mazanec DJ. Back pain: medical evaluation and therapy. Cleve Clin J Med 1995;62:163-8.

2. Wedge JH. The natural history of spinal degeneration. In: Kirkaldy-Willis WH, editor. Managing low back pain. New York: Harcourt Brace/Churchill Livingstone; 1983. p.3-8.

3. Paine KW. Clinical features of lumbar spinal stenosis. Clin Orthop Relat Res 1976;(115):77-82.

4. Hall S, Bartleson JD, Onofrio BM, Baker HL Jr, Okazaki H, O’Duffy JD. Lumbar spinal stenosis. Clinical features, diagnostic procedures, and results of surgical treatment in 68 patients. Ann Intern Med 1985;
103:271-5.

5. Turner JA, Ersek M, Herron L, Deyo R. Surgery for lumbar spinal stenosis. Attempted meta-analysis of the literature. Spine (Phila Pa 1976) 1992;17:1-8.

6. Thomas NW, Rea GL, Pikul BK, Mervis LJ, Irsik R, McGregor JM. Quantitative outcome and radiographic comparisons between laminectomy and laminotomy in the treatment of acquired lumbar stenosis. Neurosurgery 1997;41:567-74.

7. Herron LD, Trippi AC. L4-5 degenerative spondylolisthesis. The results of treatment by decompressive laminectomy without fusion. Spine (Phila Pa 1976) 1989;14:534-8.

8. Postacchini F, Cinotti G, Perugia D, Gumina S. The surgical treatment of central lumbar stenosis. Multiple laminotomy compared with total laminectomy. J Bone Joint Surg Br 1993;75:386-92.

9. Deyo RA, Ciol MA, Cherkin DC, Loeser JD, Bigos SJ. Lumbar spinal fusion. A cohort study of complications, reoperations, and resource use in the Medicare population. Spine (Phila Pa 1976) 1993;18:1463-70.

10. Nakai O, Ookawa A, Yamaura I. Long-term roentgenographic and functional changes in patients who were treated with wide fenestration for central lumbar stenosis. J Bone Joint Surg Am 1991;73:1184-91.

11. Tuli SM, Kapoor V, Jain AK, Jain S. Spinaplasty following lumbar laminectomy for multilevel lumbar spinal stenosis to prevent iatrogenic instability. Indian J Orthop 2011;45:396-403.

12. Eisenstein S. Lumbar vertebral canal morphometry for computerised tomography in spinal stenosis. Spine (Phila Pa 1976) 1983;8:187-91.

13. Sihvonen T, Herno A, Paljarvi L, Airaksinen O, Partanen J, Tapaninaho A. Local denervation atrophy of paraspinal muscles in postoperative failed back syndrome. Spine (Phila Pa 1976) 1993;18:575-81.

14. Sangwan SS, Aggarwal S, Mittal R, Kundu ZS, Siwach RC. Easy and economical alternative to the reltonhall frame for posterior spinal surgeries. J Orthop Surg (Hong Kong) 2003;7:139-41.

15. Robertson PA, Grobler LJ, Novotny JE, Katz JN. Postoperative spondylolisthesis at L4-5. The role of facet joint morphology. Spine (Phila Pa 1976) 1993;18: 1483-90.

16. Bresnahan L, Ogden AT, Natarajan RN, Fessler RG. A biomechanical evaluation of graded posterior element removal for treatment of lumbar stenosis: com- 
parison of a minimally invasive approach with two standard laminectomy techniques. Spine (Phila Pa 1976) 2009;34:17-23.

17. Young S, Veerapen R, O'Laoire SA. Relief of lumbar canal stenosis using multilevel subarticular fenestrations as an alternative to wide laminectomy: preliminary report. Neurosurgery 1988;23:628-33.

18. Benz RJ, Garfin SR. Current techniques of decompression of the lumbar spine. Clin Orthop Relat Res 2001;(384):75-81.

19. Yuan PS, Booth RE Jr, Albert TJ. Nonsurgical and surgical management of lumbar spinal stenosis. Instr Course Lect 2005;54:303-12.

20. Resnick DK, Choudhri TF, Dailey AT, et al. Guidelines for the performance of fusion procedures for degenerative disease of the lumbar spine. Part 10: fusion following decompression in patients with stenosis without spondylolisthesis. J Neurosurg Spine 2005;2:686-91.

21. Grob D, Humke T, Dvorak J. Degenerative lumbar spinal stenosis. Decompression with and without arthrodesis. J Bone Joint Surg Am 1995;77:1036-41.

22. Aryanpur J, Ducker T. Multilevel lumbar laminotomies: an alternative to laminectomy in the treatment of lumbar stenosis. Neurosurgery 1990;26:429-32.
23. Storm PB, Chou D, Tamargo RJ. Lumbar spinal stenosis, cauda equina syndrome, and multiple lumbosacral radiculopathies. Phys Med Rehabil Clin N Am 2002;13:713-33.

24. Weiner BK, Patel NM, Walker MA. Outcomes of decompression for lumbar spinal canal stenosis based upon preoperative radiographic severity. J Orthop Surg Res 2007;2:3.

25. Paine KW. Results of decompression for lumbar spinal stenosis. Clin Orthop Relat Res 1976;(115):96100.

26. Amundsen $\mathrm{T}$, Weber $\mathrm{H}$, Nordal HJ, Magnaes B, Abdelnoor M, Lilleas F. Lumbar spinal stenosis: conservative or surgical management?: A prospective 10year study. Spine (Phila Pa 1976) 2000;25:1424-35.

27. Chen LH, Lai PL, Tai CL, Niu CC, Fu TS, Chen WJ. The effect of interspinous ligament integrity on adjacent segment instability after lumbar instrumentation and laminectomy--an experimental study in porcine model. Biomed Mater Eng 2006;16:261-7.

28. Asgarzadie F, Khoo LT. Minimally invasive operative management for lumbar spinal stenosis: overview of early and long-term outcomes. Orthop Clin North Am 2007;38:387-99. 